\title{
Cancer stem cells in solid tumors: elusive or illusive?
}

\author{
Yvonne Welte1, James Adjaye1 , Hans R Lehrach ${ }^{1}$ and Christian RA Regenbrecht*1,2
}

\begin{abstract}
During the past years in vivo transplantation experiments and in vitro colony-forming assays indicated that tumors arise only from rare cells. These cells were shown to bear self-renewal capacities and the ability to recapitulate all cell types within an individual tumor. Due to their phenotypic resemblance to normal stem cells, the term "cancer stem cells" is used. However, some pieces of the puzzle are missing: (a) a stringent definition of cancer stem cells in solid tumors (b) specific markers that only target cells that meet the criteria for a cancer stem cell in a certain type of tumor. These missing parts started an ongoing debate about which is the best method to identify and characterize cancer stem cells, or even if their mere existence is just an artifact caused by the experimental procedures. Recent findings query the cancer stem cell hypothesis for solid tumors itself since it was shown in xenograft transplantation experiments that under appropriate conditions tumor-initiating cells are not rare.

In this review we critically discuss the challenges and prospects of the currently used major methods to identify cancer stem cells. Further on, we reflect the present discussion about the existence of cancer stem cells in solid tumors as well as the amount and characteristics of tumor-initiating cells and finally provide new perspectives like the correlation of cancer stem cells and induced pluripotent cells.
\end{abstract}

\section{Review} Introduction

Already 150 years ago, the German pathologist Rudolf Virchow postulated in his theory of the cellular pathology that cancer initiates from immature cells [1]. But it still took 100 years until Sajiro Makino introduced the term "tumor stem cell" for a small subpopulation of cells that were insensitive to chemotherapy and had chromosomal features different from the bulk of cells [2]. In the 1970s in vivo transplantation experiments and in vitro colonyforming assays supported Makino's observation that tumors could arise from rare cells with self-renewal capacities. Experiments indicated that these cells are able to recapitulate all cell types within an individual tumor and establish immortal cell lines [3-5].

These so called cancer stem cells (CSC) have been proposed to originate either from malignant transformation of a normal somatic stem cell or a progenitor cell [6] (Figure 1). Since stem cells proliferate throughout life they are more susceptible to accumulate oncogenic mutations

* Correspondence: regenbre@molgen.mpg.de

1 Department of Vertebrate Genomics, Max Planck Institute for Molecular Genetics, Ihnestrasse 63-73, 14195 Berlin, Germany

Full list of author information is available at the end of the article than differentiated cells with their comparatively short life span $[7,8]$.

On the other hand, it could be that differentiated cells reacquire stem cell-like characteristics by the reactivation of signaling pathways like the Wnt-beta-catenin and Bmil pathway or certain Hox genes that facilitate selfrenewal and are linked to malignant transformation of cells [9-11].

One of the great advantages of the cancer stem cell hypothesis is that it also helps understanding other cancer concepts such as cancer as a minimal residual disease. Even a single cell that evades the surgeon's blade or adjuvant therapies by acquired resistance like effective DNA repair mechanisms or high amounts of active ABC transporters that rapidly efflux chemotherapeutics recapitulates the whole tumorigenesis resulting in a relapse after what seems like a successful cancer treatment.

If the cancer stem cell hypothesis holds true at least for some tumor entities, this calls for new pharmacological perspectives to efficiently target these cells to prevent relapse and metastasis. While specific cell surface markers for CSCs in hematological malignancies are widely accepted and the concept of only a rare subpopulation of cancer cells that exhibit stem cell-like characteristics and 


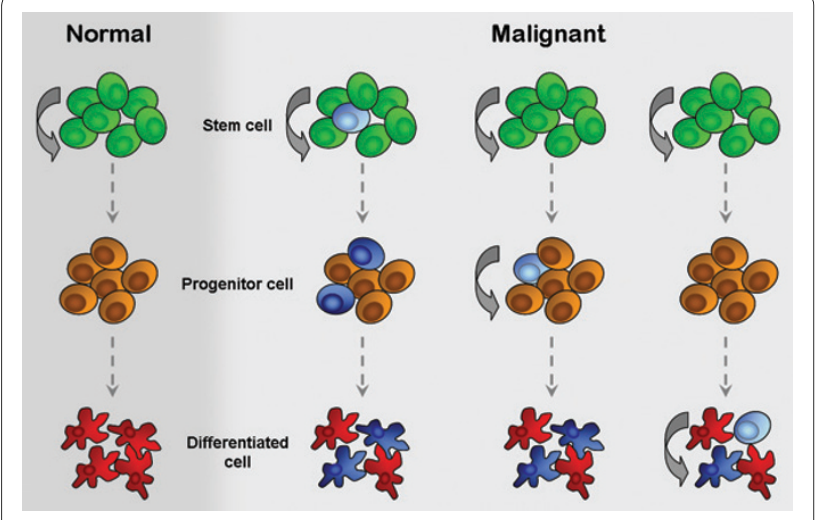

Figure 1 Origin of Cancer stem cells. In normal tissue, stem cells (green) divide asymmetrically into progenitor cells (orange) from which then terminally differentiated cells (red) are produced (left). In tumorigenesis mutations can transform stem cells into cancer stem cells (light blue) which then result in tumorigenic progenitor cells and differentiated tumor cells (dark blue). But also, by mutations in developmental pathways progenitor cells and differentiated cells can re-acquire stem cell-like properties and turn into cancer stem cells (right).

promote growth of hematological tumors is far beyond any doubt, the situation looks totally different in solid tumors. Whereas some scientists still argue about the best method to identify and characterize CSCs, others already query the CSC hypothesis in solid tumors itself since it was shown in xenograft transplantation models that under appropriate conditions tumor-initiating cells are not rare [12]. Much of the confusion in the field comes from the varying definitions of cancer stem cells. For example, asymmetric cell division vs. self-renewal: any cell that divides to give two daughter cells identical to the parental cells has self-renewed, and presumably the majority of cells within a tumor that are dividing selfrenew in this sense. Thus, there must be more to a definition of a cancer stem cell than self-renewal. The key is whether a cell can yield multiple different sub-populations cells within a tumor that found a hierarchy within the tumor by asymmetric cell division.

In this review we discuss the prospects and challenges of the currently used main methods to identify CSCs. Further on, we reflect the present discussion about the existence of CSCs as well as the amount and characteristics of tumor-initiating cells and finally provide new perspectives like the correlation of CSCs and induced pluripotent cells.

\section{Current standards of identification}

The identification of a putative cancer stem cell subpopulation with validated methods and markers for each tumor entity remains controversial. So far, researchers take advantage of known stem cell characteristics like the ability to self-renew, expression of stem cell markers and their multipotency. The most widely accepted assays to validate a candidate cancer stem cell subpopulation are efflux analysis of the DNA-binding dye Hoechst as well as detection of known stem cell markers in cancer cells and verification by xenotransplantations.

\section{Cell surface markers}

In the last decade several molecular properties have been utilized to identify and characterize CSCs from different hematopoietic and solid tumors. The first markers used were cell surface proteins already known to define stem and progenitor cells, e.g. CD133 and CD166. Furthermore, molecules that facilitate drug resistance in cancer cells like $A B C B 1$ and $A B C G 2$ were added to the list of putative CSC markers as well as proteins for which no involvement in stemness or cancerogenesis was known, e.g. CD20. In the following section we discuss examples of proposed markers which were mostly used to identify CSCs of solid tumors in the past.

CD133 (also known as Prominin 1), a member of pentaspan transmembrane glycoproteins, is expressed in hematopoietic stem cells, endothelial progenitor cells, neuronal and glial stem cells [13-15] and specifically localizes to cellular protrusions [16]. CD133 has previously also been shown to be expressed in subpopulations of cancer cells from brain, colon, lung, melanoma and other solid tumors. This led to the assumption that CD133 expressing tumor cells have stem cell or progenitor like properties and CD133 was proposed as CSC marker [7,17-19].

To illustrate the correlation of CD133 expression with the level of differentiation of a certain cell type, the group of Huttner generated an antibody that recognizes CD133 independently of potential posttranslational modifications as glycosylation. They found that the expression of CD133 is independent from the cell's state of differentiation, while posttranslational glycosylation negatively correlates with differentiation [20]. Only AC133, the glycosylated epitope of CD133, is downregulated upon cell differentiation. Therefore it seems likely that upon dedifferentiation of cells as observed in oncogenesis the glycosylation of CD133 (AC133) might also increase and serve as a marker for the tumorigenic potential of a cell.

Keeping this in mind, one has to be cautious when interpreting results from experiments where it is unclear if the antibody detected CD133 or AC133 as many groups in the field seem to use the term CD133 synonymously to AC133. This inattentiveness could lead to confusions in interpreting the results.

In 2007 Klein et al. have observed an increased expression of CD133 in primary and metastatic melanoma compared to melanocytic nevi [21]. Subsequently, other groups found that also in a variety of tumors such as hepatocellular and rectal cancer an increased CD133 expression corresponds with higher stage tumors and poor prognosis $[22,23]$. 
Previously, disseminated tumor cells of melanoma patients with metastatic disease have been shown to express stem cell markers CD133 and NESTIN [24]. Those disseminated tumor cells are currently under debate of being involved in the formation of metastases and correlation with poor prognosis [25]. However, beyond any doubts is the anchorage-independent growth of these disseminated tumor cells which is also a characteristic of stem cells from various types of self-renewing tissue $[26,27]$.

In cell culture experiments, antibody reactivity against CD133 has been shown to correlate with the cell cycle DNA profile of colon cancer, melanoma, and human embryonic stem cells. Cells with highest ectopic expression of CD133 had a DNA content of $4 \mathrm{~N}$ or even greater and reflect cycling cells [28]. These findings are concordant with the results of Grskovic and Liu that CD133+ cells have a higher mitotic index compared to CD133cells in the first week of cultivation $[29,30]$.

Moreover, Liu et al. showed that CD133 expression is significantly higher in recurrent glioblastoma tissue as compared to their respective primary tumors. Additionally, $\mathrm{CD} 133^{+}$cells in three primary cultured cell lines established from glioblastoma patients showed an increased expression of proteins associated with neural precursors, e.g. CD90, NESTIN and MSI1 compared to autologous CD133- cells as well as higher levels of ABCG2 and the DNA repair protein MGMT and higher mRNA levels of anti-apoptotic genes. For the first time ever, this study provided evidence that these properties contribute to the tumor's resistance to chemotherapy. $\mathrm{CD}_{133}{ }^{+} \mathrm{CSC}$ s were significantly more resistant to chemotherapeutic agents compared to autologous CD133cells [30].

$\mathrm{CD}_{133}{ }^{+}$cells within human osteosarcoma cell lines as well as human melanomas were also shown to have many CSC like properties as for example formation of spherelike colonies after cultivation under serum-free conditions $[7,31]$.

Finally, CD133+ cells of various tumor entities were shown to have an increased tumorigenic potential. For melanoma this was demonstrated for the first time by Monzani and collegues. Magnetically sorted $\mathrm{CD}_{133^{+}}$and CD133- cells respectively, were injected into NOD-SCID mice. After 40-50 days, mice injected with $\mathrm{CD} 133^{+}$cells developed detectable tumors, whereas mice injected with CD133- melanoma cells did not develop neoplasia even 4 months after injection [7].

In addition to its role as a cancer stem cell marker, CD133 could also serve as an important therapeutic target for metastatic melanoma and potentially for other CD133 expressing cancer types. In 2008, Rappa et al. investigated the effects of CD133 down-regulation in human metastatic melanoma, which result in slower cell growth, reduced cell motility, decreased capacity to form spheres under stem cell-like growth conditions and reduced capacity of the cells to metastasize. Monoclonal antibodies directed against two different epitopes of the CD133 protein induced a specific, dose-dependent cytotoxic effect. In cells with only residual CD133 expression, microarray analysis revealed expression changes for 143 annotated genes. $13 \%$ of the up-regulated genes coded for Wnt inhibitors [32]. In it's normal function Wnt signaling is crucial for tissue homeostasis and self-renewal in a variety of adult tissues as well as embryonic development and hematopoesis [33,34]. Additionally Wnt has been implicated as being one of the drivers of oncogenesis in various organs [35-37].

However, previous experiments revealed that some tumor cells, which do not express CD133, are also capable of self-renewal and are tumorigenic. For human gliomas Wang et al. demonstrated that CD133- cells derived from 6 different patients were tumorigenic when implanted into brains of nude rats. For 3 of these patients, analysis showed that the resulting tumors contained CD133 positive cells [38].

Even more contradictory are the results in C6 glioma cells: Whereas Zhou et al. demonstrated that this cell line contains only a small fraction of cells that can form tumor spheres in serum-free stem cell medium and express stem cell markers CD133 and NESTIN [39], Zheng et al. concluded that the C6 line is mainly composed of CSCs, although many of them are CD133- [40]. Each of the tested single C6 cells was able to generate a clone and subclones in serum-containing medium, which subsequently gave rise to a xenograft glioma in nude mice. The latter group confirmed these results the following year showing that most $\mathrm{C} 6$ cells are cancer stem-like cells with characteristics of self-renewal, multilineage differentiation potentials in vitro, and tumorigenic capacity in vivo irrespective of their CD133 expression [41].

$\mathrm{CD}_{133^{+}}$and $\mathrm{CD} 133^{-}$cells of lung cancer were also examined for their abilities of colony formation, selfrenewal, proliferation, differentiation and invasion, as well as resistance to chemotherapeutic drugs. The results suggested that both the $\mathrm{CD}_{133^{+}}$and CD133- subpopulations contain similar numbers of cancer stem cells since they displayed similar abilities [42]. Analogical results were obtained for human metastatic colon cancer cells [43].

Despite the fact that not all groups concurrently used the $\mathrm{AC} 133$ antibody to isolate $\mathrm{CD} 133^{+}$cells, the choice of antibody would explain these contradictory findings only to some extent. Even research groups that investigated the same cell type with the same type of antibodies arrived at different conclusions regarding the use of CD133/AC133 as CSC marker [39,41]. Taken together, 
CD133/AC133 is an indicator, but definitely not a reliable marker for defining a population of CSCs in solid tumors since it does not characterize tumor-initiating cells exclusively. Therefore CD133/AC133 should be seen as a necessary however insufficient criterion to identify CSCs in solid tumors.

Comparably controversial results as for CD133 were obtained from the investigations of various ATP-Binding Cassette $(\mathrm{ABC})$ transporters. Schatton et al. described tumor-initiating cells capable of self-renewal and differentiation in human melanoma defined by expression of the chemoresistance mediator ABCB5. ABCB5 expression in tumor cells correlates with clinical melanoma progression. In serial xenotransplantation experiments $\mathrm{ABCB}^{+}$melanoma cells were more tumorigenic than ABCB5- cells. Additionally, ABCB5- cells showed no differentiation capacity since they exclusively gave rise to $\mathrm{ABCB} 5$ - cells whereas $\mathrm{ABCB}^{+}$cells regenerated both subpopulations. Using a monoclonal anti-ABCB5 antibody in nude mice, initial tumor growth as well as growth of established tumors was inhibited by antibody-dependent cell-mediated cytotoxicity in $\mathrm{ABCB}^{+}$cells [44]. Monzani et al. identified a subpopulation of human melanoma cells co-expressing $\mathrm{ABCB} 1, \mathrm{ABCB} 5$ and $\mathrm{ABCC} 2$ in addition to stem cell markers which demonstrated higher clonogenicity, self-renewal capacity and anchorage-independent growth than the negative fraction [45]. Furthermore, they identified tumor-initiating cells in human melanoma by the expression of ABCG2 which is coexpressed with CD133 [7]. For colon, breast and prostate cancer cell lines however, these results could not be confirmed [46]. Patrawala et al. compared $\mathrm{ABCG}^{+}$and ABCG2- cancer cells with respect to their tumorigenicity in vivo, but no significant difference in tumor incidence or latency periods comparing the two populations was observed [46]. Finally, Quintana et al. examined the expression of more than 50 surface markers on melanoma cells and injected these cells into NOD/SCID mice lacking the interleukin-2 gamma receptor. In every case, tumors arose from all fractions of cells. No known marker distinguished tumorigenic from non-tumorigenic cells [12].

Concluding these results, it seems as if tumor-initiating cells are phenotypically heterogeneous and no marker or set of markers has been found to identify CSCs in solid tumors in general nor for specific tumor entities.

\section{Dye exclusion assays}

In contrast to preferably cell-type specific surface markers, the use of Hoechst-dye to identify and isolate CSCs as a so called side population (SP) overcomes the barrier of phenotypical markers and replaces it by more direct functional markers [47]. The blue fluorescent Hoechst 33342 is a cell permeable bisbenzimidazole derivative that binds to the minor groove of DNA. After excitation of Hoechst its emission can be measured simultaneously in the blue and red spectrum. But although Hoechst enters viable cells, it is also actively pumped out by ATPBinding Cassette $(\mathrm{ABC})$ transporters of the cell membrane [48-50]. Goodell et al. were the first to identify that hematopoietic stem cells are particularly effective at pumping out Hoechst [51] since they express high levels of $\mathrm{ABC}$ transporters resulting in a small side population of weakly stained cells which can be observed during flow cytometric analysis. To determine the size of the side population, verapamil, an L-type calcium channel blocking agent serves as an important control. Blocking the calcium channels inhibits the efflux of Hoechst-dye from these cells, so it is then possible to gate for the side-population, which is suspected to consist of cancer stem cells. Subsequently, side populations were identified in various established cell lines from breast cancer, lung cancer and glioblastoma, suggesting that this phenotype defines a class of cancer stem cells with inherently high resistance to chemotherapeutic agents due to rapid efflux of those compounds [52]. Kondo et al. were the first to come up with the hypothesis that the side population resembles the source of CSCs in C6 glioma cells since only SP cells initiated tumors in multiple tissues in nude mice [53]. Also, purified side population cells from breast cancer and thyroid cell lines showed higher tumorigenicity than corresponding non-side population cells. They have a differential gene expression profile and preferentially express genes related to stemness, including $\mathrm{NOTCH1}$ and CTNNB1 at higher levels [46,54]. Grichnik et al. identified side population cells in metastatic melanoma cell lines which, compared to non-side population cells were small in size, less melanized, had a decreased proliferation rate and gave rise to a heterogeneous cell population [55]. All these findings support the isolation of side populations via Hoechst staining as an identification method for CSCs. Additionally, this method could help to identify more specific molecular CSC markers by comparing the expression profiles of SP and non-SP cells which is crucial for the establishment of targeted cancer therapies.

The main criterion of CSCs in contrast to non-CSCs is their unique capability to differentiate and recapitulate all cell types within a tumor. The results of several groups led to the conclusion that the analysis of a SP via Hoechst staining is a useful technique to isolate putative CSCs. They demonstrated that only SP cells generate both SP and non-SP cells in cell culture while non-SP cells fail to do so $[52,53,56,57]$. Furthermore, they were able to initiate tumors in xenograft transplantation experiments with very low numbers of SP cells, whereas non-SP cells were either not at all tumorigenic or only upon injection of multifold more cells compared to the SP. 
In contrast to these encouraging findings, results from studies with thyroid, gastrointestinal, adrenocortical and glioma cancer cells question the possibility to identify CSCs by their efflux-capacity. They depict very well that non-SP cells are able to generate SP cells, have similar growth rates and tumor-initiating capacity as SP cells [54,58-60].

The same controversial results were obtained regarding the expression of specific stem cell/CSC markers on SP cells. Although it was previously shown that intestinal epithelial stem cells can be isolated as a side population (SP) by FACS after staining with Hoechst [61] this concept did not apply to gastrointestinal cancer cells tested by Burkert et al. [58]. SP cells of several gastrointestinal cancer cell lines showed no increased expression of stem cell markers like CD133, CD44, Musashi-1, Oct-4 and CD117 compared to non-SP cells. Both fractions were similarly clonogenic in vitro, tumorigenic in vivo, and displayed similar differentiation potential in vitro and in vivo.

$A B C$ transporters that most notably account for the efflux of Hoechst are ABCG2 (Bcrp1) and Mdr-1 (also known as P-glycoprotein or ABCB1) [48,50,51,62,63]. This is concordant with the findings that these genes are highly expressed on SP cells but not on non-SP cells [46,52]. Congruously, putative CSCs in the SP have greater capacity to expel cytotoxic drugs used in cancer therapy, therefore improve their survival and finally recapitulate the whole tumorigenesis resulting in a relapse after what seems like a successful cancer treatment $[52,64]$.

However, expression levels of ABCG2 and Mdr-1 was shown to be identical on non-SP and SP cells in gastrointestinal cancer indicating that there may be additional factors responsible for the Hoechst effluxing property [58]. Furthermore, other studies showed that side population cells obviously express some transporter molecules responsible for Hoechst efflux. But this alone seems to be insufficient to ensure chemotherapy resistance associated with a survival benefit over non-SP cells [59].

A good example of the influence of technical factors on the results is the comparison of studies from Kondo et al. and Patrawala et al. Both groups studied the same cell lines, but the yield of SP cells varied among the magnitude of 10 [46,53].

Due to these controversial findings some scientists argue that Hoechst staining and isolation of SP cells cannot be applied to identify and isolate CSCs, at least for some tumor entities.

We think these controversial results are mostly due to inefficient and lenient sorting procedures that never result in 100\% pure CSC and non-CSC fractions. Variations in the staining protocol and FACS procedure can have enormous influence on the yield, viability and homogeneity of side population cells, affecting all later analyses done with these cells. In order to gain reproducible results, tissue dissociation to single cell suspension levels and cell counting need to be optimized. Optimal Hoechst concentration should be independently determined for each new tissue studied and the optimal Hoechst concentration should be within the plateau region [65]. But Hoechst concentration is exactly the parameter that mostly differs among published data. Used concentrations ranged from $2-10 \mu \mathrm{g} / \mathrm{ml}$ and the incubation time from 30-120 minutes [53,55,66-71].

Furthermore, it has been shown that various cell types are unequally sensitive to verapamil which serves as an important control. Nethertheless, most groups apply a concentration of $50 \mu \mathrm{M}$ verapamil without determining the cell-line specific sensitivity prior to the SP sorting $[46,55,67]$.

The reasons to explain the differences between Kondo et al. and Patrawala et al. range from the use of different flow cytometers and modified protocols [46]. Indeed, Patrawala's group used higher Hoechst concentrations than Kondo and according to studies from Kunkel higher Hoechst concentrations result in a smaller SP [53]. Patrawala et al. therefore legitimately reasoned that their experimental setup was more stringent for the identification of putative CSCs [46].

In addition to the technical aspects of FACS sorting, it was demonstrated that the SP size depends on the density of cells in culture. SP cells preferentially survive at very low plating density, because such clonal growth favors the presence of CSCs [54].

Due to the range of parameters that can dramatically influence SP analyses, results from such sorting experiments should be compared very critically. Optimized and standardized protocols for each cell type as well as stringent cell culture and isolation settings are required to eliminate the risk of analyzing different SP cells. These standards will help to abolish skepticism and uncertainty about the general validity of the technique and potential of SP cells.

Ultimately, the toxicity of Hoechst should be addressed and always kept in mind when applying this dye to isolate putative CSCs. As Hoechst binds to DNA, it can disrupt DNA replication during cell division. Consequently, it is potentially mutagenic and carcinogenic. What causes the researcher to adhere to strict safety regulations while working with Hoechst, also affects all cells that are stained in vitro. Already in 1986, Siemann et al. evaluated the toxicity of this stain in cells derived from sarcomas. Hoechst toxicity increased with increasing exposure times resulting in 25- to 45 -fold reduced survival in irradiated cells and 4- to 5 -fold reduced survival in untreated cells. Furthermore, cytotoxic effects of Hoechst 33342 were found to be significantly greater in cells in the $\mathrm{S}$ 
phase than in cells in G1 and G2-M phases of the cell cycle [72]. Recently, these results were confirmed by Shen et al. They showed that Hoechst staining leads to obvious morphological alterations and increased apoptosis in the C6 glioma cell line [41]. This toxicity, particularly its cell cycle specificity, suggests a potentially severe limitation for the use of Hoechst dye in combination with fluorescence activated cell sorting. Non-SP cells with lower capacity to efflux this dye will suffer more from its effects compared to putative CSCs of the SP. Hence, Wu et al. argued that SP cells may not represent stem-like cells, but rather, a population of cells that is able to escape the lethal effects of Hoechst staining [73].

An alternative to the use of Hoechst provides the use of Rhodamine 123 which was shown to be non-toxic to cells even at high concentrations [74]. The cell-permeable, green-fluorescent Rhodamine 123 binds to mitochondrion membranes. Like Hoechst it is actively pumped out of the cells by $\mathrm{ABC}$ transporters, e.g. MDR1 and ABCB1 [75,76]. Liu et al. compared the use of Rhodamine 123 and Hoechst to isolate CSCs in a hepatocellular cell line. The percentages of SP and non-SP after staining with Rhodamine 123 or Hoechst were the same as well as the proliferative abilities in vitro, expression of stem cell markers and tumorigenicities in vivo of both obtained side populations [77]. Taken together, use of Rhodamine 123 in combination with flow cytometric cell sorting may be a useful method for CSC identification.

\section{In vivo transplantation experiments - are CSCs rare cells?}

Until today the gold standard in validating a putative CSC fraction is their transplantation into immunodeficient mice. If CSCs are really enriched in this population, these cells should have a several fold higher capacity to form tumors compared to the control fraction where the cells lack this CSC marker or the typical characteristics as rapid efflux of Hoechst due to high expression of $A B C$ transporters.

In this manner, the side population after Hoechst staining and flow cytometric analysis was proved to be enriched of tumor-initiating cells in thyroid [54], ovarian [78] and breast cancer [46], glioma [46,53], melanoma [70] and hepatocellular carcinoma [79]. Further on, xenotransplantation experiments validated certain CSC markers like ABCB5 for melanoma [44], CD133 for melanoma [7], lung [19] and colon cancer $[18,80]$ and CD20 for melanoma [81].

Until two years ago, it seemed that only few cells isolated from a tumor have the ability to initiate tumor growth in transplantation experiments. But in 2008 Quintana et al. put this dogma of rare CSCs at least for melanoma into question. They found out that melanomainitiating cells are only rare in NOD/SCID mice if monitoring tumor formation for a short term, like most researcher do, and using the common assays described in literature.

But this frequency could be significantly increased by following melanoma formation for more than 8 weeks, using NOD/SCID IL2R $\gamma^{\text {null }}$ mice that lack natural killer cell activity compared to NOD/SCID mice and injecting melanoma cells together with Matrigel, a mixture of structural proteins and growth factors. Overall, after injection of single, unselected melanoma cells, $27 \%$ initiated a tumor suggesting that so far the frequency of melanoma-initiating cells was significantly underestimated [12].

With this modified assay Quintana et al. provided a good example of the importance of interactions between tumor cells and their extracellular matrix and how they dictate whether or not a tumor develops from a mutated cell.

Matrigel represents a rich store of matrix proteins as well as angiogenic and growth factors which promote tumor growth and metastasis [82]. But still the aberrant extracellular matrix of immunodeficient mice cannot substitute for all factors of the human microenvironment, and the stem cell niche which is crucial to initiate tumor growth is not reconstituted in xenotransplantation models [83].

This is supported by studies that show that the frequency of cells that sustain tumor growth was dramatically increased using allograft transplantation models. Kelly et al. transferred mouse lymphoma cells into nonirradiated histocompatible recipient mice. Regardless of cell number injected, all animals developed a tumor even when transplanting only a single neoplastic cell [84]. Additionally, studies using spontaneously arising tumors in syngeneic rodents have shown that the number of cells required to transplant a tumor depends on the site of transplantation and the type of cells [85].

Last but not least, the amount of tumor-initiating cells is influenced by the experimental setup. Enzyme treatment during the preparation of the cell suspensions and sorting procedure might decrease the viability of tumor cells and modify protein expression, thereby affecting the population into which the cells are sorted and the ability of these proteins to play a role in tumor formation following transplantation [86].

But instead of focusing on the establishment of methods to increase the percentage of tumor-initiating cells in artificial xenograft transplantation models with immunosuppressed mice, should we not answer the question which cells initiate tumors in healthy organisms with intact immune systems as well as resist cancer therapies and causing relapses, respectively? In 2009 Schatton and Frank proposed that CSCs in human melanoma that express the chemoresistance mediator ABCB5 might be responsible for melanoma immune evasion [87]. Thus, 
immunomodulation might represent the key mechanism by which CSCs promote tumorigenic growth.

\section{Cancer stem cells, quo vadis?}

Models serve the purpose of simplifying complex contexts. Traditionally, signaling cascades are depicted as straight forward processes in a highly ordered manner. This way of looking at biological systems started a true gold rush in the field of stem cell marker identification. So, in the past much effort was made to identify novel key cancer stem cell markers for specific tumor entities, if not a universal marker or set of markers for CSCs in all cancers. But in reality the biology with all its feedback loops, branching, positive and negative modulators is much more complex. This makes it a challenge to identify the right components that uniquely define cancer stem cells.

On the other hand standards are needed to help interpreting the results of various groups working on the elucidation of CSC nature. But into which direction should it be leading to? Which methods, which protocols are going to be the right ones?

One approach for the characterization of CSCs that was not considered yet, could be the analysis of analogies between cancer stem cells and induced pluripotent stem (iPS) cells.

In 2006 Takahashi and Yamanaka were the first who successfully reversed differentiated mouse embryonic or adult fibroblasts into pluripotent stem cells by introducing only the four factors Oct3/4, Sox2, c-Myc and Klf4 and named these reprogrammed cells which exhibit the morphology and growth properties of embryonic stem (ES) cells and express ES cell marker genes, induced pluripotent stem cells [88].

After inducing somatic cells with these four "Yamanaka factors", Mikkelsen and colleagues found out that about $20 \%$ of the cells stained positive for the stem-cell marker SSEA1, but only about $1.2 \%$ were fully reprogrammed. Whereas fully reprogrammed cells showed gene expression and epigenetic states similar to that of ES cells, gene expression profiling revealed that partially reprogrammed cells re-activated only a small group of genes related to stem cell renewal and maintenance, but yet these cells are not pluripotent. Instead they exhibit a down-regulation of structural genes and regulatory factors expressed in differentiated cells and up-regulation of some lineage-specific and proliferative genes not expressed in iPS cells [89].

Potentially, the same is true for cancer stem cells. Probably they represent an intermediate state between stem cells and differentiated cells like partially reprogrammed cells do between iPS cells and differentiated cells (Figure 2). Mikkelsen $e t$ al. showed that these differences are due to epigenetic events like persistent DNA hypermethylation at pluripotency- and germ-cell-specific loci [89].

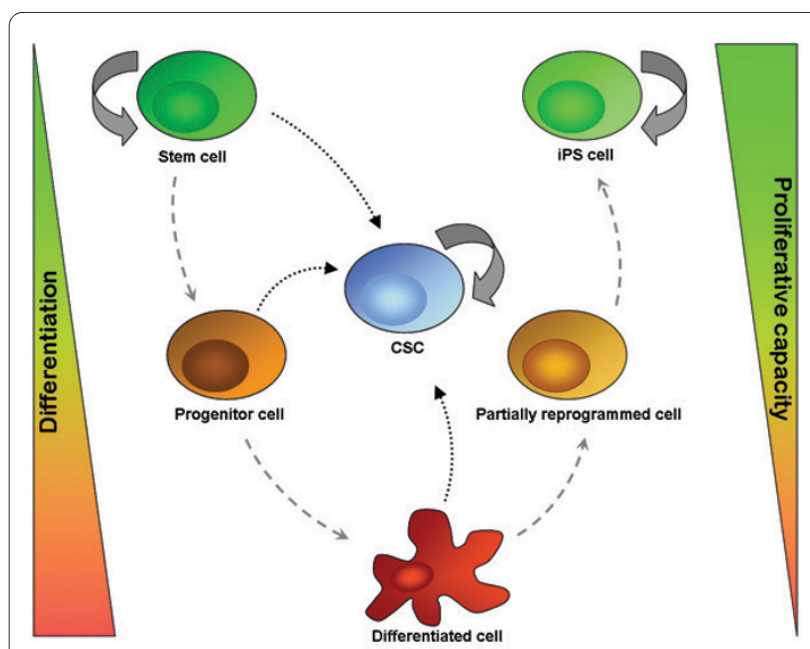

Figure 2 Relationship between stem cell species. Stem cells are characterized by their ability to form many different types of tissues and their capacity to self-renew. With increasing level of differentiation from progenitor cell to differentiated cell, the plasticity reduces as does the proliferative capacity. Cancer stem cells form at the interface between stem cell and progenitor cells. This phenomenon has lately also been credited to iPS cells and their partially reprogrammed precursors.

In addition, it is known that small molecules like the histone deacetylase inhibitor valproic acid, the DNA methyltransferase inhibitor 5-aza-cytidine or the kinase inhibitor Kenpaullone facilitate iPS cell formation by modeling epigenetic information [90-92].

The comparison of melanoma cells enriched for cancer stem cells and non-cancer stem cells in our lab also argues in favor of epigenetic regulation and maintenance of the phenotype or alternative splicing since we found no differences in coding mutations at the genome or transcriptome level but tremendous varieties among gene expression patterns (unpublished data).

This is also consistent with the plasticity of cancer because only epigenetic modulations can efficiently be activated and reverted in short intervals. This model has been recently discussed by Gupta et al. They postulated that there might exist a dynamic equilibrium between CSCs and non-CSCs within tumors that may be shifted in one direction or another by contextual signals within the tumor microenvironment that influence the probability of interconversion between the CSC and non-CSC compartments [93]. This would also explain the varying amounts of cancer stem cells within the same tumor entity described by different groups.

Evidence for a conversion of CSC into non-CSCs and vice versa were given by Platet et al. and Lichtenauer et al. Both groups found that non-SP cells in flow cytometric analyses after Hoechst staining are able to generate SP cells $[59,60]$. That means bulk tumor cells can convert into CSCs and explains the maintenance of the SP phenotype in long-term cell cultures. This dynamic equilibrium 
was also seen within the partially reprogrammed cells in the group of Jaenisch where cells positive for SSEA1 as well as cells negative for this stem cell marker reverted to the heterogeneous state within 1-2 passages in cell culture [89].

But still one question remains unsolved. How is this equilibrium driven and which cells transmit the required signals? Are the non-CSC alone really able to de-differentiate into CSC or do they obtain the priming signals to reconstitute the balance within the tumor microenvironment from the small part of CSCs. MicroRNAs probably play a role in facilitating the equilibrium of CSCs and non-CSCs like they promote iPS cell formation by their regulatory effects on epigenetic and transcriptional modulation [94]. We should learn from this quite new but extensively investigated research field and try consigning these new insights to the CSC research.

One - of course provocative - interpretation of the seemingly contradictive findings on CSCs is that cancer stem cells are neither a defined nor a definable sub-population of cells within the tumor, but rather a highly dynamic state in which only few cells at a time are in. We learn from Heisenberg's "uncertainty principle" that in a single experiment only the position (= state) or speed (= change over time) can be determined with any given precision. This principle does not only hold true for quantum mechanics, but also applies to observation made on living cells. For example by sorting the cells for their stem cell-like properties, the result is only a snapshot of the cells' state, but we cannot deduce from this observation that also the bulk cells cannot acquire such properties. On the other hand, if we follow the dynamic changes in the level of markers, we cannot determine whether this comes from an increase in cells expressing the marker, or if the expression level per cell has increased. Keeping this in mind one has to be very careful when interpreting the current literature on cancer stem cells.

\section{Conclusions}

Since Nixon's war on cancer billions of dollars were invested in cancer research. But still, our understanding of the biology of cancer does not help to cure this dreadful disease. The concept of cancer stem cells was very welcome because it opened new perspectives in understanding and ultimately healing this disease.

Although it is tempting to explain tumor formation and metastasis by the presence of stem cells, after almost a decade of intense research, it seems that cancer stem cells still do not explain how neoplasias evolve. The inconsistencies in the experiments call for a more in depth analysis of the cellular and signaling features of those cells. The research therefore must focus on two things: (a) the establishment of robust and reliable criteria to identify and isolate cancer stem cells and (b) in parallel research- ers must find and agree on an unbiased definition of what a cancer stem cell really is. This may be the activation/ deactivation of specific pathways or the presence/absence of expression of proteins that discriminate them from other cells within the tumor.

In the worst case, many of the observations made in cancer stem cells would be nothing but artefacts, which are induced by the researcher by the artificial environment that is presented to the cells in form of the conditions under which the cells are cultured. But even then, the existence of subpopulations of cells with unique features helped to make researchers more sensitive towards the heterogeneity not only within a tumor in vivo, but also in cell culture models in vitro.

From what we know about cancer stem cells today, we would not expect the worst case to become true. It seems more and more likely that this population of cells is not a defined group of cells resting in a niche and populating the tumor with amplifying cells, but that few or maybe even many cells within the tumor can function as cancer stem cells if induced, but also can go back to the state of a "normal" cancer cell. Of course this scenario makes it even more difficult to target these cells for therapeutic reasons. Although, research has shed some light on the matter, the question still remains unanswered: Are CSCs in solid tumors elusive, or illusive?

\section{Competing interests}

The authors declare that they have no competing interests.

\section{Authors' contributions}

YW and CRAR contributed to the writing and conceptual design and preparation the figures of this review. All authors have read and approved the final manuscript.

\section{Acknowledgements}

We grateful thank the Berliner Krebsgesellschaft and Wilhelm Sander-Stiftung for supporting our work. The authors also would like to thank Prof. M. Dietel, Prof. R. Schäfer and Prof. P. Schlag for the warm welcome at the Institute for Pathology and Comprehensive Cancer Center Charité as well as Sonja Probst, Stephanie Seibt and Ellen Hilgenberg for fruitful discussions and critically reading the manuscript.

\section{Author Details}

1 Department of Vertebrate Genomics, Max Planck Institute for Molecular Genetics, Ihnestrasse 63-73, 14195 Berlin, Germany and 2Laboratory for Molecular Tumorpathology and Comprehensive Cancer Center Charité Charitéplatz 1, 10117 Berlin, Germany

Received: 20 January 2010 Accepted: 11 May 2010 Published: 11 May 2010

References

1. Virchow R: Die Cellularpathologie in ihrer Begrundung aufphysiologische und pathologische Gewebelehre Berlin: August Hirschwald; 1858.

2. Makino S: The role of tumor stem-cells in regrowth of the tumor following drastic applications. Acta Unio Int Contra Cancrum 1959, 15(Suppl 1):196-198.

3. Hamburger A, Salmon SE: Primary bioassay of human myeloma stem cells. J Clin Invest 1977, 60:846-854.

4. Hamburger AW, Salmon SE: Primary bioassay of human tumor stem cells. Science 1977, 197:461-463.

5. Park CH, Bergsagel DE, McCulloch EA: Mouse myeloma tumor stem cells: a primary cell culture assay. J Nat/ Cancer Inst 1971, 46:411-422. 
6. Reya T, Morrison SJ, Clarke MF, Weissman IL: Stem cells, cancer, and cancer stem cells. Nature 2001, 414:105-111.

7. Monzani E, Facchetti F, Galmozzi E, Corsini E, Benetti A, Cavazzin C, Gritti A, Piccinini A, Porro D, Santinami M, et al:: Melanoma contains CD133 and ABCG2 positive cells with enhanced tumourigenic potential. Eur J Cancer 2007, 43:935-946.

8. Morris RJ: Keratinocyte stem cells: targets for cutaneous carcinogens. $J$ Clin Invest 2000, 106:3-8.

9. Reya T, Clevers H: Wnt signalling in stem cells and cancer. Nature 2005 , 434:843-850.

10. Lessard J, Sauvageau G: Bmi-1 determines the proliferative capacity of normal and leukaemic stem cells. Nature 2003, 423:255-260.

11. Regenbrecht $\mathrm{CR}$, Lehrach $\mathrm{H}$, Adjaye J: Stemming Cancer: Functional Genomics of Cancer Stem Cells in Solid Tumors. Stem Cell Rev 2008, 4(4):319-28

12. Quintana E, Shackleton M, Sabel MS, Fullen DR, Johnson TM, Morrison SJ: Efficient tumour formation by single human melanoma cells. Nature 2008, 456:593-598.

13. Kobari L, Giarratana MC, Pflumio F, Izac B, Coulombel L, Douay L: CD133+ cell selection is an alternative to CD34+ cell selection for ex vivo expansion of hematopoietic stem cells. J Hematother Stem Cell Res 2001, 10:273-281.

14. Quirici N, Soligo D, Caneva L, Servida F, Bossolasco P, Deliliers GL: Differentiation and expansion of endothelial cells from human bone marrow CD133(+) cells. Br J Haematol 2001, 115:186-194.

15. Pfenninger CV, Roschupkina T, Hertwig F, Kottwitz D, Englund E, Bengzon J, Jacobsen SE, Nuber UA: CD133 is not present on neurogenic astrocytes in the adult subventricular zone, but on embryonic neural stem cells, ependymal cells, and glioblastoma cells. Cancer Res 2007, 67:5727-5736.

16. Corbeil D, Roper K, Hellwig A, Tavian M, Miraglia S, Watt SM, Simmons PJ, Peault B, Buck DW, Huttner WB: The human AC133 hematopoietic stem cell antigen is also expressed in epithelial cells and targeted to plasma membrane protrusions. J Biol Chem 2000, 275:5512-5520.

17. Singh SK, Hawkins C, Clarke ID, Squire JA, Bayani J, Hide T, Henkelman RM, Cusimano MD, Dirks PB: Identification of human brain tumour initiating cells. Nature 2004, 432:396-401

18. leta K, Tanaka F, Haraguchi N, Kita Y, Sakashita H, Mimori K, Matsumoto T, Inoue $\mathrm{H}$, Kuwano $\mathrm{H}$, Mori M: Biological and genetic characteristics of tumor-initiating cells in colon cancer. Ann Surg Oncol 2008, 15:638-648.

19. Bertolini G, Roz L, Perego P, Tortoreto M, Fontanella E, Gatti L, Pratesi G, Fabbri A, Andriani F, Tinelli S, et al:: Highly tumorigenic lung cancer CD133+ cells display stem-like features and are spared by cisplatin treatment. Proc Natl Acad Sci USA 2009, 106:16281-16286.

20. Florek M, Haase M, Marzesco AM, Freund D, Ehninger G, Huttner WB, Corbeil D: Prominin-1/CD133, a neural and hematopoietic stem cell marker, is expressed in adult human differentiated cells and certain types of kidney cancer. Cell Tissue Res 2005, 319:15-26.

21. Klein WM, Wu BP, Zhao S, Wu H, Klein-Szanto AJ, Tahan SR: Increased expression of stem cell markers in malignant melanoma. Mod Pathol 2007, 20:102-107.

22. Song W, Li H, Tao K, Li R, Song Z, Zhao Q, Zhang F, Dou K: Expression and clinical significance of the stem cell marker CD133 in hepatocellular carcinoma. Int J Clin Pract 2008, 62:1212-1218.

23. Wang Q, Chen ZG, Du CZ, Wang HW, Yan L, Gu J: Cancer stem cell marker CD133+ tumour cells and clinical outcome in rectal cancer. Histopathology 2009, 55:284-293

24. Fusi A, Busse A, Ochsenreiter S, Rietz A, Keilholz U: Expression of stem cell markers in circulating melanoma cells. 2009 ASCO Annual Meeting Proceedings (Post-Meeting Edition), (May 20 Supplement): I Clin Oncol 2009, 27(No 15S):e22056.

25. Ossowski L, Aguirre-Ghiso JA: Dormancy of metastatic melanoma. Pigment Cell Melanoma Res 2010, 23(1):41-56. Epub 2009 Oct 19

26. Toma JG, Akhavan M, Fernandes KJ, Barnabe-Heider F, Sadikot A, Kaplan DR, Miller FD: Isolation of multipotent adult stem cells from the dermis of mammalian skin. Nat Cell Biol 2001, 3:778-784.

27. Reynolds BA, Weiss S: Generation of neurons and astrocytes from isolated cells of the adult mammalian central nervous system. Science 1992, 255:1707-1710.

28. Jaksch M, Munera J, Bajpai R, Terskikh A, Oshima RG: Cell cycledependent variation of a CD133 epitope in human embryonic stem cell, colon cancer, and melanoma cell lines. Cancer Res 2008, $68: 7882-7886$
29. Grskovic B, Ruzicka K, Karimi A, Qujeq D, Muller MM: Cell cycle analysis of the CD133+ and CD133- cells isolated from umbilical cord blood. Clin Chim Acta 2004, 343:173-178.

30. Liu G, Yuan X, Zeng Z, Tunici P, Ng H, Abdulkadir IR, Lu L, Irvin D, Black KL, Yu JS: Analysis of gene expression and chemoresistance of CD133+ cancer stem cells in glioblastoma. Mol Cancer 2006, 5:67.

31. Tirino V, Desiderio V, d'Aquino R, De Francesco F, Pirozzi G, Graziano A Galderisi U, Cavaliere C, De Rosa A, Papaccio G, Giordano A: Detection and characterization of CD133+ cancer stem cells in human solid tumours. PLOS ONE 2008, 3:e3469.

32. Rappa G, Fodstad O, Lorico A: The stem cell-associated antigen CD133 (Prominin-1) is a molecular therapeutic target for metastatic melanoma. Stem Cells 2008, 26:3008-3017.

33. Gat U, DasGupta R, Degenstein L, Fuchs E: De Novo hair follicle morphogenesis and hair tumors in mice expressing a truncated betacatenin in skin. Cell 1998, 95:605-614

34. Espada J, Calvo MB, Diaz-Prado S, Medina V: Wnt signalling and cancer stem cells. Clin Transl Oncol 2009, 11:411-427.

35. Korinek V, Barker N, Moerer P, van Donselaar E, Huls G, Peters PJ, Clevers H: Depletion of epithelial stem-cell compartments in the small intestine of mice lacking Tcf-4. Nat Genet 1998, 19:379-383.

36. Taipale J, Beachy PA: The Hedgehog and Wnt signalling pathways in cancer. Nature 2001, 411:349-354.

37. Larue L, Delmas V: The WNT/Beta-catenin pathway in melanoma. Front Biosci 2006, 11:733-742.

38. Wang J, Sakariassen PO, Tsinkalovsky O, Immervoll H, Boe SO, Svendsen A, Prestegarden L, Rosland G, Thorsen F, Stuhr L, et al: CD133 negative glioma cells form tumors in nude rats and give rise to $C D 133$ positive cells. Int J Cancer 2008, 122:761-768.

39. Zhou XD, Wang XY, Qu FJ, Zhong YH, Lu XD, Zhao P, Wang DH, Huang QB, Zhang L, Li XG: Detection of cancer stem cells from the $\mathrm{C} 6$ glioma cell line. J Int Med Res 2009, 37:503-510.

40. Zheng X, Shen G, Yang X, Liu W: Most C6 cells are cancer stem cells: evidence from clonal and population analyses. Cancer Res 2007, 67:3691-3697.

41. Shen G, Shen F, Shi Z, Liu W, Hu W, Zheng X, Wen L, Yang X: Identification of cancer stem-like cells in the $\mathrm{C} 6$ glioma cell line and the limitation of current identification methods. In Vitro Cell Dev Biol Anim 2008, 44:280-289

42. Meng X, Li M, Wang X, Wang Y, Ma D: Both CD133+ and CD133subpopulations of $\mathrm{A} 549$ and $\mathrm{H} 446$ cells contain cancer-initiating cells. Cancer Sci 2009, 100:1040-1046.

43. Shmelkov SV, Butler JM, Hooper AT, Hormigo A, Kushner J, Milde T, St Clair $\mathrm{R}$, Baljevic M, White I, Jin DK, et al:: CD133 expression is not restricted to stem cells, and both CD133+ and CD133- metastatic colon cancer cells initiate tumors. J Clin Invest 2008, 118:2111-2120.

44. Schatton T, Murphy GF, Frank NY, Yamaura K, Waaga-Gasser AM, Gasser M, Zhan Q, Jordan S, Duncan LM, Weishaupt C, et al.: Identification of cells initiating human melanomas. Nature 2008, 451:345-349.

45. Keshet Gl, Goldstein I, Itzhaki O, Cesarkas K, Shenhav L, Yakirevitch A Treves AJ, Schachter J, Amariglio N, Rechavi G: MDR1 expression identifies human melanoma stem cells. Biochem Biophys Res Commun 2008, 368:930-936.

46. Patrawala L, Calhoun T, Schneider-Broussard R, Zhou J, Claypool K, Tang DG: Side population is enriched in tumorigenic, stem-like cancer cells, whereas ABCG2+ and ABCG2- cancer cells are similarly tumorigenic. Cancer Res 2005, 65:6207-6219.

47. Hadnagy A, Gaboury L, Beaulieu R, Balicki D: SP analysis may be used to identify cancer stem cell populations. Exp Cell Res 2006, 312:3701-3710.

48. Scharenberg CW, Harkey MA, Torok-Storb B: The ABCG2 transporter is an efficient Hoechst 33342 efflux pump and is preferentially expressed by immature human hematopoietic progenitors. Blood 2002, 99:507-512.

49. Zhou S, Morris JJ, Barnes Y, Lan L, Schuetz JD, Sorrentino BP: Bcrp1 gene expression is required for normal numbers of side population stem cells in mice, and confers relative protection to mitoxantrone in hematopoietic cells in vivo. Proc Natl Acad Sci USA 2002, 99:12339-12344.

50. Zhou S, Schuetz JD, Bunting KD, Colapietro AM, Sampath J, Morris JJ, Lagutina I, Grosveld GC, Osawa M, Nakauchi H, Sorrentino BP: The ABC transporter Bcrp1/ABCG2 is expressed in a wide variety of stem cells and is a molecular determinant of the side-population phenotype. Nat Med 2001, 7:1028-1034. 
51. Goodell MA, Brose K, Paradis G, Conner AS, Mulligan RC: Isolation and functional properties of murine hematopoietic stem cells that are replicating in vivo. J Exp Med 1996, 183:1797-1806

52. Hirschmann-Jax C, Foster AE, Wulf GG, Nuchtern JG, Jax TW, Gobel U, Goodell MA, Brenner MK: A distinct "side population" of cells with high drug efflux capacity in human tumor cells. Proc Natl Acad Sci USA 2004 101:14228-14233

53. Kondo T, Setoguchi T, Taga T: Persistence of a small subpopulation of cancer stem-like cells in the C6 glioma cell line. Proc Natl Acad Sci USA 2004, 101:781-786.

54. Mitsutake N, Iwao A, Nagai K, Namba H, Ohtsuru A, Saenko V, Yamashita S: Characterization of side population in thyroid cancer cell lines: cancer stem-like cells are enriched partly but not exclusively. Endocrinology 2007, 148:1797-1803

55. Grichnik JM, Burch JA, Schulteis RD, Shan S, Liu J, Darrow TL, Vervaert CE, Seigler HF: Melanoma, a tumor based on a mutant stem cell? J Invest Dermatol 2006, 126:142-153.

56. Wang J, Guo LP, Chen LZ, Zeng YX, Lu SH: Identification of cancer stem cell-like side population cells in human nasopharyngeal carcinoma cell line. Cancer Res 2007, 67:3716-3724.

57. Wang YH, Li F, Luo B, Wang XH, Sun HC, Liu S, Cui YQ, Xu XX: A side population of cells from a human pancreatic carcinoma cell line harbors cancer stem cell characteristics. Neoplasma 2009, 56:371-378.

58. Burkert J, Otto WR, Wright NA: Side populations of gastrointestinal cancers are not enriched in stem cells. J Pathol 2008, 214:564-573.

59. Lichtenauer UD, Shapiro I, Geiger K, Quinkler M, Fassnacht M, Nitschke R, Ruckauer KD, Beuschlein F: Side population does not define stem celllike cancer cells in the adrenocortical carcinoma cell line NCI h295R. Endocrinology 2008, 149:1314-1322.

60. Platet N, Mayol JF, Berger F, Herodin F, Wion D: Fluctuation of the SP/ non-SP phenotype in the C6 glioma cell line. FEBS Lett 2007, 581:1435-1440.

61. Dekaney CM, Rodriguez JM, Graul MC, Henning SJ: Isolation and characterization of a putative intestinal stem cell fraction from mouse jejunum. Gastroenterology 2005, 129:1567-1580.

62. Chaudhary PM, Roninson IB: Expression and activity of P-glycoprotein, a multidrug efflux pump, in human hematopoietic stem cells. Cell 1991, 66:85-94.

63. Schinkel AH, Smit JJ, van Tellingen O, Beijnen JH, Wagenaar E, van Deemter L, Mol CA, Valk MA van der, Robanus-Maandag EC, te Riele HP, et al:: Disruption of the mouse mdr1a P-glycoprotein gene leads to a deficiency in the blood-brain barrier and to increased sensitivity to drugs. Cell 1994, 77:491-502.

64. Hirschmann-Jax C, Foster AE, Wulf GG, Goodell MA, Brenner MK: A distinct "side population" of cells in human tumor cells: implications for tumor biology and therapy. Cell Cycle 2005, 4:203-205.

65. Montanaro F, Liadaki K, Schienda J, Flint A, Gussoni E, Kunkel LM Demystifying SP cell purification: viability, yield, and phenotype are defined by isolation parameters. Exp Cell Res 2004, 298:144-154.

66. Haraguchi N, Utsunomiya T, Inoue H, Tanaka F, Mimori K, Barnard GF, Mori M: Characterization of a side population of cancer cells from human gastrointestinal system. Stem Cells 2006, 24:506-513.

67. Asakura A, Rudnicki MA: Side population cells from diverse adult tissues are capable of in vitro hematopoietic differentiation. Exp Hematol 2002, 30:1339-1345

68. Fukaya R, Ohta S, Yamaguchi M, Fujii H, Kawakami Y, Kawase T, Toda M: Isolation of cancer stem-like cells from a side population of a human glioblastoma cell line, SK-MG-1. Cancer Lett 2010, 291(2):150-7. Epub 2009 Nov 13

69. Mimeault M, Batra SK: Characterization of nonmalignant and malignant prostatic stem/progenitor cells by Hoechst side population method. Methods Mol Biol 2009, 568:139-149.

70. Dou J, Wen P, Hu W, Li Y, Wu Y, Liu C, Zhao F, Hu K, Wang J, Jiang C, et al.: Identifying tumor stem-like cells in mouse melanoma cell lines by analyzing the characteristics of side population cells. Cell Biol Int 2009, 33:807-815

71. Bhattacharya S, Jackson JD, Das AV, Thoreson WB, Kuszynski C, James J, Joshi S, Ahmad I: Direct identification and enrichment of retinal stem cells/progenitors by Hoechst dye efflux assay. Invest Ophthalmol Vis Sci 2003, 44:2764-2773
72. Siemann DW, Keng PC: Cell cycle specific toxicity of the Hoechst 33342 stain in untreated or irradiated murine tumor cells. Cancer Res 1986, 46:3556-3559

73. Wu C, Alman BA: Side population cells in human cancers. Cancer Lett 2008, 268:1-9.

74. Ribou AC, Vigo J, Kohen E, Salmon JM: Microfluorometric study of oxygen dependence of (1"-pyrene butyl)-2-rhodamine ester probe in mitochondria of living cells. J Photochem Photobiol B 2003, 70:107-115.

75. Martin C, Walker J, Rothnie A, Callaghan R: The expression of Pglycoprotein does influence the distribution of novel fluorescent compounds in solid tumour models. Br J Cancer 2003, 89:1581-1589.

76. Kugawa F, Suzuki T, Miyata M, Tomono K, Tamanoi F: Construction of a model cell line for the assay of MDR1 (multi drug resistance gene-1) substrates/inhibitors using HeLa cells. Pharmazie 2009, 64:296-300.

77. Liu WH, Qian NS, Li R, Dou KF: Replacing Hoechst33342 with Rhodamine 123 in isolation of cancer stem-like cells from the MHCC97 cell line. Toxicol In Vitro 2010, 24(2):538-45. Epub 2009 Nov 12

78. Szotek PP, Pieretti-Vanmarcke R, Masiakos PT, Dinulescu DM, Connolly D, Foster R, Dombkowski D, Preffer F, Maclaughlin DT, Donahoe PK: Ovarian cancer side population defines cells with stem cell-like characteristics and Mullerian Inhibiting Substance responsiveness. Proc Natl Acad SCi USA 2006, 103:11154-11159.

79. Chiba T, Kita K, Zheng YW, Yokosuka O, Saisho H, Iwama A, Nakauchi H, Taniguchi $\mathrm{H}$ : Side population purified from hepatocellular carcinoma cells harbors cancer stem cell-like properties. Hepatology 2006, 44:240-251.

80. Ricci-Vitiani L, Lombardi DG, Pilozzi E, Biffoni M, Todaro M, Peschle C, De Maria R: Identification and expansion of human colon-cancer-initiating cells. Nature 2007, 445:111-115.

81. Fang D, Nguyen TK, Leishear K, Finko R, Kulp AN, Hotz S, Van Belle PA, Xu X, Elder DE, Herlyn M: A tumorigenic subpopulation with stem cell properties in melanomas. Cancer Res 2005, 65:9328-9337.

82. Kleinman HK, Martin GR: Matrigel: basement membrane matrix with biological activity. Semin Cancer Biol 2005, 15:378-386.

83. Bissell MJ, Labarge MA: Context, tissue plasticity, and cancer: are tumo stem cells also regulated by the microenvironment? Cancer Cell 2005, 7:17-23.

84. Kelly PN, Dakic A, Adams JM, Nutt SL, Strasser A: Tumor growth need not be driven by rare cancer stem cells. Science 2007, 317:337.

85. Hewitt HB, Blake E, Proter EH: The effect of lethally irradiated cells on the transplantability of murine tumours. Br $\lrcorner$ Cancer 1973, 28:123-135.

86. Hill RP: Identifying cancer stem cells in solid tumors: case not proven. Cancer Res 2006, 66:1891-1895.

87. Schatton T, Frank MH: Antitumor immunity and cancer stem cells. Ann NYAcad Sci 2009, 1176:154-169.

88. Takahashi K, Yamanaka S: Induction of pluripotent stem cells from mouse embryonic and adult fibroblast cultures by defined factors. Cell 2006, 126:663-676.

89. Mikkelsen TS, Hanna J, Zhang X, Ku M, Wernig M, Schorderet P, Bernstein $B E$, Jaenisch $R$, Lander ES, Meissner A: Dissecting direct reprogramming through integrative genomic analysis. Nature 2008, 454:49-55

90. Huangfu D, Maehr R, Guo W, Eijkelenboom A, Snitow M, Chen AE, Melton DA: Induction of pluripotent stem cells by defined factors is greatly improved by small-molecule compounds. Nat Biotechnol 2008, 26:795-797.

91. Wernig M, Lengner CJ, Hanna J, Lodato MA, Steine E, Foreman R, Staerk J, Markoulaki S, Jaenisch R: A drug-inducible transgenic system for direct reprogramming of multiple somatic cell types. Nat Biotechnol 2008, 26:916-924

92. Lyssiotis CA, Foreman RK, Staerk J, Garcia M, Mathur D, Markoulaki S, Hanna J, Lairson LL, Charette BD, Bouchez LC, et al.: Reprogramming of murine fibroblasts to induced pluripotent stem cells with chemical complementation of Klf4. Proc Natl Acad Sci USA 2009, 106:8912-8917.

93. Gupta PB, Chaffer CL, Weinberg RA: Cancer stem cells: mirage or reality? Nat Med 2009, 15:1010-1012.

94. Chen L, Liu L: Current progress and prospects of induced pluripotent stem cells. Sci China C Life Sci 2009, 52:622-636.

doi: 10.1186/1478-811X-8-6

Cite this article as: Welte et al., Cancer stem cells in solid tumors: elusive or illusive? Cell Communication and Signaling 2010, 8:6 